\title{
3 Research Square

\section{Optimization of the Pulsed Arc Welding Parameters for Wire Arc Additive Manufacturing in Austenitic Steel Applications}

\section{Anatoliy Zavdoveev ( $\sim$ avzavdoveev@gmail.com )}

Paton Electric Welding Institute of NAS of Ukraine https://orcid.org/0000-0003-2811-0765

Valeriy Pozniakov

Paton Electric Welding Institute of NAS of Ukraine

Thierry Baudin

Université Paris-Saclay

Hyoung Seop Kim

Pohang University of Science and Technology

llya Klochkov

Paton Electric Welding Institute of NAS of Ukraine

Sviatoslav Motrunich

Paton Electric Welding Institute of NAS of Ukraine

Mark Heaton

ANT, Advanced Nano Technology

Philippe Aquier

AddUp FRANCE, 5 rue bleue

Massimo Rogante

Rogante Engineering Office

Anatoliy Denisenko

Paton Electric Welding Institute of NAS of Ukraine

Alex Gajvoronskiy

Paton Electric Welding Institute of NAS of Ukraine

Mykola Skoryk

G. V. Kurdyumov Institute of Metal Physics of the NAS of Ukraine

\section{Research Article}

Keywords: wire arc additive manufacturing, direct energy deposition, pulsed arc welding, microstructure, mechanical properties

Posted Date: October 13th, 2021 
DOl: https://doi.org/10.21203/rs.3.rs-964589/v1

License: (c) (1) This work is licensed under a Creative Commons Attribution 4.0 International License. Read Full License

Version of Record: A version of this preprint was published at The International Journal of Advanced Manufacturing Technology on January 14th, 2022. See the published version at https://doi.org/10.1007/s00170-022-08704-4. 


\title{
Optimization of the pulsed arc welding parameters for wire arc additive manufacturing in austenitic steel applications
}

Anatoliy Zavdoveev ${ }^{1}$, Valeriy Pozniakov ${ }^{1}$, Thierry Baudin ${ }^{2}$, Hyoung Seop Kim³ ${ }^{3}$,llya Klochkov ${ }^{1}$, Sviatoslav

Motrunich $^{1}$, Mark Heaton ${ }^{4}$, Philippe Aquier ${ }^{5}$, Massimo Rogante ${ }^{6}$, Anatoliy Denisenko ${ }^{1}$, Alex Gajvoronskiy ${ }^{1}$, Mykola Skoryk $^{7}$

${ }^{1}$ Paton Electric Welding Institute of NAS of Ukraine, Bozhenko n. 11, 03680 Kiev, Ukraine, avzavdoveev@gmail.com

${ }^{2}$ Université Paris-Saclay, CNRS, Institut de chimie moléculaire et des matériaux d'Orsay, 91405 Orsay, France, thierry.baudin@universite-paris-saclay.fr

${ }^{3}$ Pohang University of Science and Technology, Department of Materials Science and Engineering, (POSTECH), Pohang 37673, Korea hskim@postech.ac.kr

${ }^{4}$ ANT, Advanced Nano Technology, Nandor Rd, Park West business park, Dublin, mark.heaton@antsltd.com

${ }^{5}$ AddUp FRANCE, 5 rue bleue, ZI de Ladoux, 63118 Cébazat, France, e-mail: philippeacquier@yahoo.fr

${ }^{6}$ Rogante Engineering Office, Contrada San Michele n.61, 62012 Civitanova Marche, Italy, main@roganteengineering.it

${ }^{7}$ G. V. Kurdyumov Institute of Metal Physics of the NAS of Ukraine; Kyiv, Ukraine, mykolaskor@gmail.com

\begin{abstract}
Industrial development continues to present challenges for manufacturers. One of them is additive manufacturing ( $\mathrm{AM}$ ) with metallic materials. One promising solution is wire arc additive manufacturing (WAAM). Currently, WAAM is a more promising tool for developers, firstly due to the simplicity of its realization and secondly for its cost-effectiveness. Building materials are represented by welding wires, so the deposition rate is favorable. A pulse power source is commonly used in this scheme of realization. Much less attention has been paid to the optimization of the power source working regime, i.e., welding mode. Indeed, the power determines the whole process of WAAM. Therefore, in the present work, an attempt has been made to perform a scientifically based design for the optimal welding mode. The austenitic welding wire was chosen to eliminate phase-transition effects in the solid state of the deposited metal. As a result of the investigation, the advantages of the designed welding mode for WAAM application are made clear. Successful efforts have been made to optimize welding modes for WAAM applications. This study is important for manufacturers as well as engineers and scientists.
\end{abstract}

Keywords: wire arc additive manufacturing; direct energy deposition; pulsed arc welding; microstructure; mechanical properties 


\section{Abbreviations}

EBSD - electron backscatter diffraction

EDS - energy dispersive spectrometry

GMAW - gas metal arc welding

HAZ - heat affected zone

HB - Brinell hardness

HV - Vickers hardness

PA-GMAW - pulse arc gas metal arc welding (low-frequency pulse arc welding)

PC-GMAW - pulse current gas metal arc welding

PD - penetration depth

SEM - scanning electron microscopy

SW - seam width

UTS - ultimate tensile stress

WAAM - wire arc additive manufacturing

WG - welds geometry

WTC - welding thermal cycle

YS - yield stress 


\section{Introduction}

Additive Manufacturing (AM) is the technology of layer-by-layer building up and manufacturing objects and parts [1-3]. For example, a Space $X$ rocket engine is assembled from thousands of parts. Additive manufacturing approaches the challenge of such products by printing complex components using a single operation to transform raw materials into final products. This approach significantly reduces the number of parts due to complex manufacturing.

Just one rocket component typically corresponds to thousands of small parts made using traditional manufacturing methods. Multiple additive manufacturing techniques exist in the world. There are many ways to implement AM today. One method is an electron beam, while another is a laser source with individual filler materials. There is also wire arc technology. Among them, wire arc additive manufacturing (WAAM) is the most promising for cost-effective producing large metallic components for the construction industry. The heating source in this scheme is an electric arc, and the filler material is commercial welding wire. The combination of these two factors provides valuable advantages and benefits over high-energy laser or electron beam tools.

Significant raw material savings are possible compared to conventional machining and forging approaches [4]. WAAM does not require specific tooling as in casting and forging. The manufacturing costs are much lower particularly for lowvolume production, and cycle times are significantly reduced [5]. Additionally, the ability to use wire as a feedstock provides high-efficiency material deposition. The main benefit of the WAAM process is its low capital investment. The processing characteristics make the WAAM process preferable over alternative fusion sources. Compared to laser-based methods, the use of the electrical arc offers a higher efficiency fusion source [6]. This is advantageous in terms of energy consumption, especially for reflective metal alloys having poor laser coupling efficiency. Examples include aluminum, copper [7], and magnesium [8]. Typical layer heights are 1-2 mm for surface waviness of $500 \mu \mathrm{m}$ [9] and deposition rates up to $10 \mathrm{~kg} / \mathrm{hr}$. WAAM productivity and metal removal are similar to laser and electron beam approaches. Advances in research and development have made the WAAM process highly functional for a number of materials [10], where static mechanical properties similar 
to those found in wrought and metal casts can be produced [11]. High-quality production of WAAM parts can only be achieved when the specific materials processing challenges related to the high level of heat input of the WAAM process are addressed.

Direct energy deposition is receiving increasing attention in additive manufacturing design research [12,13]. Considering that GMAW (gas metal arc welding) is the most widely used, it should be taken into account in the mode of operation [14]. This means maintaining special welding current, voltage, and welding speed, etc. In the complex processes, all the above-mentioned welding parameters affect the welding thermal cycle (WTC) [15]. WCT is the most important measure of the effectiveness of the welding process as it determines the structural formation and thus the properties of the final product. In this connection, determining the optimal welding parameters is a key point for successful additive manufacturing process dosing. Modern developments in welding power sources provide for the implementation of pulse technology. Commonly known pulse parameters are the amplitude and the duration of the pulse and pause. These parameters further complicate the design process [16-18]. Nevertheless, applying special project methods such as the Taguchi algorithm can solve this task $[19,20]$. A number of studies have demonstrated the effectiveness of pulse current $(P C)$ technology in traditional welding processes. In other words, PC-GMAW improves arc stabilization, decreases spattering, increases penetration depth, etc. Further development of pulsing technologies in GMAW provides additional improvements in pulse combination to obtain double pulses. The application of so-called low frequency $(f<$ $25 \mathrm{~Hz}$ ) pulsed arc welding (PA-GMAW) provides opportunities for controlling the metal crystallization process. Obviously, a good combination of the modern pulse technologies in GMAW will bring exciting benefits for facilitating additive manufacturing in large-scale production.

Thus, the main objective of this study is to develop an optimized GMAW mode for wire arc additive manufacturing and to consider its effect on the formation of the deposited metals for model walls and the mechanical properties and structural investigation of such. 


\section{Experimental Procedure}

\subsection{Direct energy deposition tool}

Currently, direct energy deposition was chosen based on the GMAW power source Phoenix Pulse 501 equipment. This power source provides a wide range of welding modes, i.e., stationary, pulse current, superpulse etc. (Figure 1). Invertertype sources possess complex characteristics of welding current dependence. In stationary mode, it has high-frequency pulsing with $f=58 \mathrm{kHz}$ (Ultrasound GMAW, US-GMAW). Such an approach offers advantages in terms of the stiffness of the welding arc and its pressure. A further improvement is pulsing the current input with a frequency ranging from 60 to $160 \mathrm{~Hz}$ (PC-GMAW). This provides benefits for arc stabilization, reduced sputtering, and improved control of the welding process. Finally, the superpulse mode represents the highest potential for WAAM applications. This explains the peculiarities of the superpulse mode, i.e., the possibility of applying low-frequency pulses of $\mathrm{f}<=25 \mathrm{~Hz}$. These pulsing conditions pave the way for regulating the crystallization processes in the weld pool. Thus, lowfrequency pulsed arc welding can be named PA-GMAW (Pulse Arc Gas Metal Arc Welding). The pulse arc definition is used in low-frequency pulsing processes because the welding arc noticeably changes its volume with cyclical peaks in the current, as shown in Figure 1.

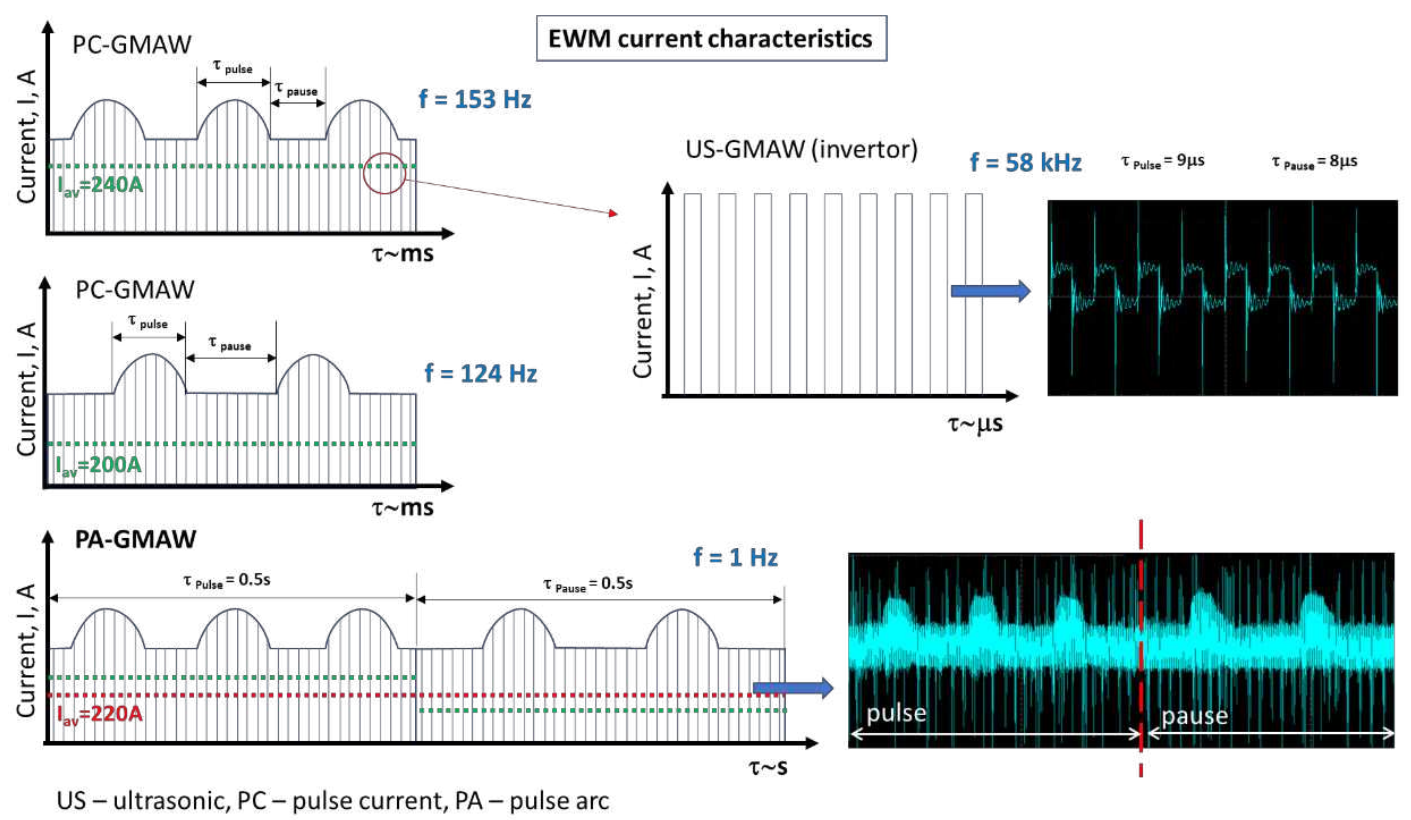


Figure 1. Waveform of pulsed current GMAW showing real-time oscillogram and schematic with waveform applied

The pulsed arc welding process has four independently controlled operating parameters: pause (base) current (Ipause), pulse current (Ipulse), frequency (f), and pulse on time (PT). The range of parameters used is determined by the task of a particular experiment. In this particular case, the currents were chosen according to the limits for low pulse currents $160 \mathrm{~A}$ and upper $240 \mathrm{~A}$, and for a pause current lower $80 \mathrm{~A}$ and upper $140 \mathrm{~A}$. These current ranges are grounded by extensive experience with $1.2 \mathrm{~mm}$ austenitic wire; that is, below $80 \mathrm{~A}$, the whole process will not be stationary. Above $240 \mathrm{~A}$, overheating as well as wide seams will form. For additive manufacturing, the abovementioned lack of control must be avoided. The pulse-on time range was set to $40-80 \%$, and finally, the frequency was set to $0.50-5$ $\mathrm{Hz}$. Below $0.5 \mathrm{~Hz}$, it is very difficult to obtain sound welds, and the whole seam becomes non-uniform. Above $5 \mathrm{~Hz}$, the effect of pulsating on the welding thermal cycle will be less explicit. Thus, the established boundaries of the pulsed arc welding (PA-GMAW) parameters are summarized in Table 1.

Table1. Parameter levels for conducting experiments on the PA-GMAW processes.

\begin{tabular}{|c|c|c|c|c|c|c|c|}
\hline \multirow[t]{3}{*}{ Parameter/Factors } & \multirow{3}{*}{ Notation } & \multicolumn{6}{|c|}{ Levels } \\
\hline & & \multicolumn{3}{|c|}{ Original } & \multicolumn{3}{|c|}{ Coded } \\
\hline & & Low & Medium & High & Low & Medium & High \\
\hline Pulsed current (A) & $A$ & 160 & 200 & 240 & 1 & 2 & 3 \\
\hline Base current (A) & B & 80 & 120 & 140 & 1 & 2 & 3 \\
\hline Frequency $(\mathrm{Hz})$ & C & 0,5 & 1 & 5 & 1 & 2 & 3 \\
\hline Pulse on time (\%) & D & 40 & 60 & 80 & 1 & 2 & 3 \\
\hline
\end{tabular}

For the welding experiments, an austenitic steel wire (deposited metal) Horda307Ti with a diameter of $1.2 \mathrm{~mm}$ was used (EN 14171, wt\%: G $188 \mathrm{Mn} \mathrm{Ti}$, chemical composition $0.10 \mathrm{C}, 0.8 \mathrm{Si}, 6.0 \mathrm{Mn}, 20.0 \mathrm{Cr}, 9.5 \mathrm{Ni}, 0.6 \mathrm{Ti})$. On the other hand, $10 \mathrm{~mm}$ thick plates made of 9MnSi5 low-carbon steel (DIN, wt\%: C 0.09, Si 0.5-0.8, Mn1.3-1.7) were used for the substrate. The choice of austenitic welding material is 
determined by the absence of a phase transformation below the $A_{c 3}$ point. This will simplify further analysis of mechanical properties and structure formation.

\subsection{Taguchi optimization routine}

Four independently controllable process variables and three experimental levels are presented in this study (Table 1). In total, for four factors and three levels, 81 experiments such as $3^{4}=81$ are required. The method proposed by Taguchi uses orthogonal arrays (OAs) to determine in real-time the minimum number of experiments for all design influences. In these experimental designs, each factor is assessed individually, and one does not affect the other. The conditions encountered in this study, i.e., four influencing parameters and three levels, are suitable for selecting the L9 matrix as a pilot project. Table 2 provides details of nine real-time experimental tests designed according to the L9 scheme $\left(3^{4}\right)$, a standard experimental design proposed by Taguchi [21,22]. However, the experiments are carried out in random order to bypass the noise source.

Table 2. Performing the trials based on the design plan and results in the tabulation

\begin{tabular}{l|cccccccc}
\multicolumn{4}{c}{} & \multicolumn{2}{c}{ Pulsed current, A } & \multicolumn{2}{c}{ Base current, A } & \multicolumn{2}{c}{ Frequency, Hz } & \multicolumn{2}{c}{ Pulse on time, \% } \\
\cline { 2 - 9 } № & Value & Code & Value & Code & Value & Code & Value & Code \\
$\mathbf{1}$ & 160 & 1 & 80 & 1 & 0,5 & 1 & 40 & 1 \\
$\mathbf{2}$ & 160 & 1 & 120 & 2 & 1 & 2 & 60 & 2 \\
$\mathbf{3}$ & 160 & 1 & 140 & 3 & 5 & 3 & 80 & 3 \\
$\mathbf{4}$ & 200 & 2 & 80 & 1 & 1 & 2 & 80 & 3 \\
$\mathbf{5}$ & 200 & 2 & 120 & 2 & 5 & 3 & 40 & 1 \\
$\mathbf{6}$ & 200 & 2 & 140 & 3 & 0,5 & 1 & 60 & 2 \\
$\mathbf{7}$ & 240 & 3 & 80 & 1 & 5 & 3 & 60 & 2 \\
$\mathbf{8}$ & 240 & 3 & 120 & 2 & 0,5 & 1 & 80 & 3 \\
$\mathbf{9}$ & 240 & 3 & 140 & 3 & 1 & 2 & 40 & 1
\end{tabular}


Nominal control of the final response of the degree of contribution of the individual process parameters has been estimated using a statistical method, namely ANOVA [23].

\subsection{Model wall building procedure details}

Based on the experimental results, the optimal PA-GMAW mode was used for WAAM wall construction and compared the PC-GMAW mod with the same average current. The wall building was performed in 5 passes at a temperature of $150{ }^{\circ} \mathrm{C}$. The first two layers are represented as buffer parts and the start of the 3rd layer is actually the model representative layer when the process is in the steady-state stage.

\subsection{Welding thermal cycle determination}

In order to study the influence of GMAW modes on the welding thermal cycles (WTC), appropriate experiments were performed. A $10 \mathrm{~mm}$ thick steel plate was used to fix the WTC (Figure 2). Chromel-alumel thermocouples were drilled into the steel plates of a depth of 7.5-8 $\mathrm{mm}$. This drilling depth is based on previous studies and requires registration of the WTC in the hear affected zone (HAZ) area.

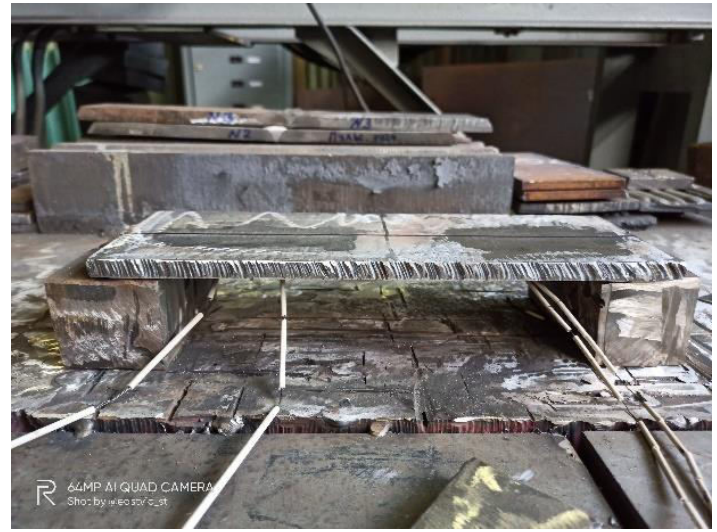

a)

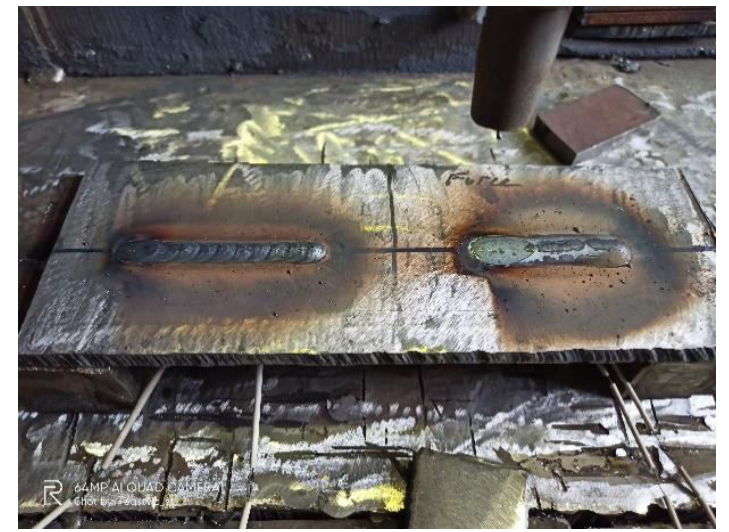

b)

Figure 2. Welding thermal cycle registration tool, side view (a), and front view(b). 


\subsection{Mechanical properties characterization}

The mechanical properties of the investigated steels, i.e., ultimate tensile strength (UTS), yield stress (YS) and plasticity ( $\delta$, elongation for failure), were determined in static tensile tests at ambient temperature. To establish the effect of the chosen technology on material strength Vickers and Brinell hardness tests were performed with loads of $100 \mathrm{~g}$ and $187.5 \mathrm{~kg}$ for $10 \mathrm{~s}$.

\subsection{Microstructure characterization}

For structural analysis, several methods were used: scanning electron microscopy (SEM, with a Tscan Mira 3 LMU facility), electron back scattering diffraction (EBSD from Oxford Instruments), and energy dispersive spectroscopy (EDS from Oxford Instruments).

Preparation of metallographic specimens for microstructural studies were carried out according to standard methods using grinding papers of various roughnesses (P240, P400, P600, P1200, P2000). Final polishing was performed on a diamond suspension with a polishing particle size of $1 \mu \mathrm{m}$. To reveal and identify the morphology of the microstructure of the specimen, etching with $4 \% \mathrm{HNO}_{3}$ solution in alcohol was conducted. The exposure time of these specimens was $4 \mathrm{~s}$, followed by washing and drying. The average grain size was evaluated by applying a linear intercept method. The chemical composition of the structural components was determined using EDS.

The crystallographic orientation of the crystallites was determined using the EBSD technique. The requirements for the surface quality of the specimens for EBSD are higher than for standard microscopy. To form high-quality diffraction patterns, surface relief must be minimized. Therefore, the specimens for EBSD were prepared using standard procedures for metallographic investigations with the exception of the finishing stage. For polishing, $0.04 \mu \mathrm{m}$ of colloidal silica solution was applied. A special MD-Nap cloth was used for polishing, the rotation frequency was $200 \mathrm{rpm}$, the pressing force of the thin section was $27 \mathrm{~N}$, and the polishing time was 
3-5 minutes. Scanning electron microscope Tescan Mira 3 LMU equipped with Nordlys detector and HKL Channel 5 software was used for EBSD analysis of structural changes. To obtain a representative sample, at least 1500 grains of the specimen were analyzed. The procedure used was to apply a magnification of ( $\mathrm{x}$ $600-700$ ) for a scanning area of $150 \times 100 \mu \mathrm{m}^{2}$, at a scanning step of $0.5 \mu \mathrm{m}$ (at least five measuring points per grain), binning $4 \times 4$. The degree of indication was at least $80 \%$.

\section{Results and discussion}

\subsection{Pulse arc welding Taguchi optimization}

According to the L9 matrix, welding was performed on the substrate with the aim of further determination of the geometry. Macro samples, as well as weld seam view, are shown in Figure 3. When carrying out developing experiments, different process parameters were used to provide different response values: penetration depth (PD), width of the HAZ at the root (HAZ), and seam width (SW). It is necessary to evaluate the influence of each selected factor using the responses received during experimental trials that are not unique and may have both desirable and undesirable characteristics. To solve the above problem, the S/N (signal-to-noise) ratio is used by the Taguchi method, which measures the deviation of a quality characteristic from a desired value. Signal is the term Taguchi uses to represent the desired values of the output characteristics, and the term noise is used to represent the unwanted values. Taking into account that the main task of the current problem is to get the min/max response (i.e., min PD, HAZ, or max SW). According to the suggested Taguchi design number of the signal-to-noise ratio, the Larger the better (LB) value must be taken.

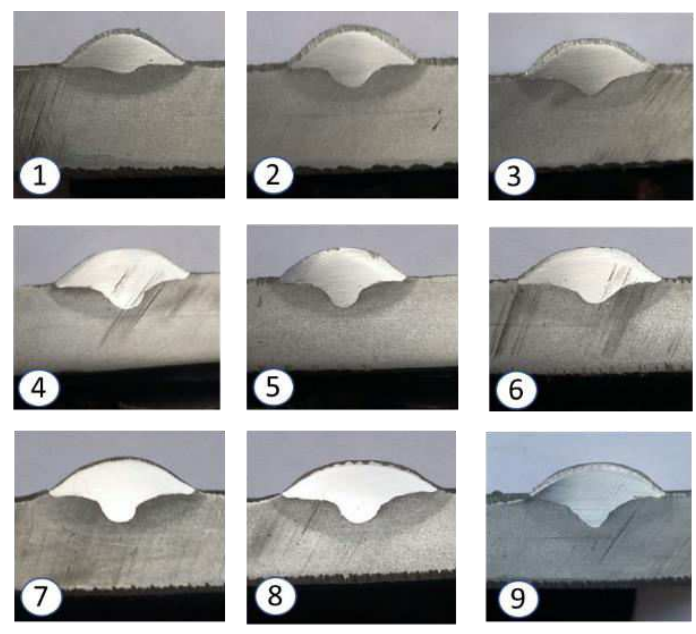

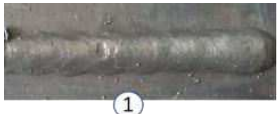
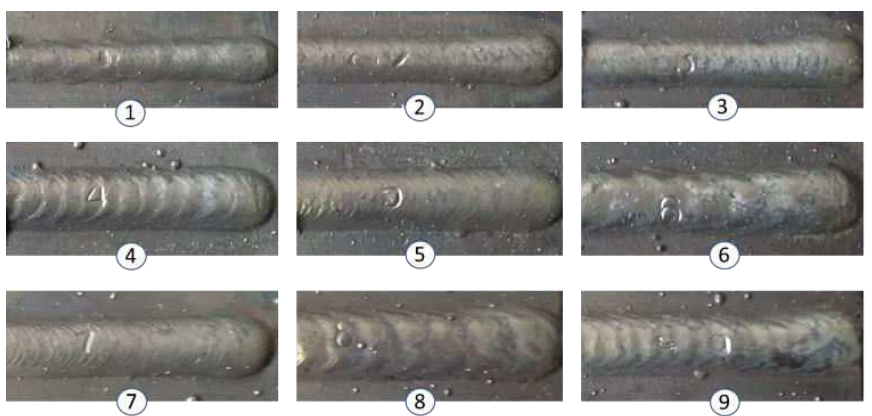

$20 \mathrm{~mm}$ 
a)

b)

Figure 3. PA-GMAW experimental weldments by L9 matrix program. a - macro samples, $b$ - welded seam view, the numbers correspond to the program numbers (Table 2).

The main goal of this experimental part is to optimize the PA-GMAW process parameters to obtain the specified weld geometry. To calculate the $S / N$ ratio of the response considered in this study, the LB characteristic (Equation 1, were $\mathrm{n}-$ number of mearsurements, $Y$ - measured parameter ) is selected. The measured numbers of the studied quantities (PD, SW, HAZ) and calculated $S / N$ ratios for all experiments are shown in Table 3.

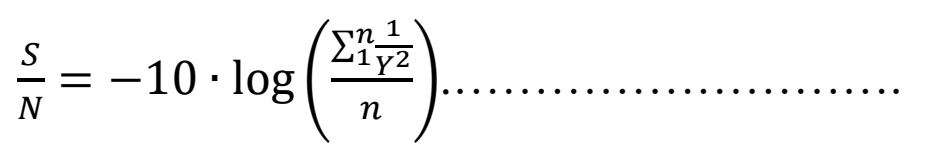

The next step in the analysis is to divide the influence of each individual parameter into all three levels considered and to rank them in the order of their impact on the response parameter. This is possible because the chosen experimental design is an orthogonal matrix L9 [24].

Table 3. Measured heat inputs and experimental results with equivalent $\mathrm{S} / \mathrm{N}$ ratios.

\begin{tabular}{|c|c|c|c|c|c|c|c|c|c|c|}
\hline \multirow{2}{*}{$\begin{array}{l}\text { Trial } \\
\text { No }\end{array}$} & \multicolumn{4}{|c|}{ Process Parameters } & \multicolumn{6}{|c|}{ Response } \\
\hline & $\begin{array}{l}I_{\text {pulse }} \\
\text { (A) }\end{array}$ & $\begin{array}{l}I_{\text {pause }} \\
\text { (A) }\end{array}$ & $\begin{array}{l}f \\
(H z)\end{array}$ & $\begin{array}{l}\text { PT } \\
(\%)\end{array}$ & PD & $\mathrm{S} / \mathrm{N}$ & SW & $\mathrm{S} / \mathrm{N}$ & HAZ & $\mathrm{S} / \mathrm{N}$ \\
\hline 1. & 160 & 80 & 0,5 & 40 & 0.88 & -1.13 & 10.81 & 20.68 & 1.89 & 5.51 \\
\hline 2. & 160 & 120 & 1 & 60 & 2.16 & 6.673 & 11.93 & 21.53 & 1.43 & 3.12 \\
\hline 3. & 160 & 140 & 5 & 80 & 2.47 & 7.851 & 12.94 & 22.24 & 1.62 & 4.21 \\
\hline 4. & 200 & 80 & 1 & 80 & 3.37 & 10.55 & 14.82 & 23.42 & 1.13 & 1.05 \\
\hline 5. & 200 & 120 & 5 & 40 & 3.31 & 10.4 & 13.87 & 22.84 & 1.12 & 0.98 \\
\hline
\end{tabular}




\begin{tabular}{|l|l|l|l|l|l|l|l|l|l|l|}
\hline $\mathbf{6 .}$ & $\mathbf{2 0 0}$ & $\mathbf{1 4 0}$ & $\mathbf{0 , 5}$ & $\mathbf{6 0}$ & 2.10 & 6.374 & 12.51 & 21.94 & 2.06 & 6.25 \\
\hline $\mathbf{7 .}$ & $\mathbf{2 4 0}$ & $\mathbf{8 0}$ & $\mathbf{5}$ & $\mathbf{6 0}$ & 2.93 & 9.322 & 14.94 & 23.48 & 1.72 & 4.68 \\
\hline $\mathbf{8 .}$ & $\mathbf{2 4 0}$ & $\mathbf{1 2 0}$ & $\mathbf{0 , 5}$ & $\mathbf{8 0}$ & 3.60 & 11.12 & 17.68 & 24.95 & 2.26 & 7.07 \\
\hline $\mathbf{9 .}$ & $\mathbf{2 4 0}$ & $\mathbf{1 4 0}$ & $\mathbf{1}$ & $\mathbf{4 0}$ & 3.35 & 10.5 & 15.01 & 23.53 & 1.82 & 5.18 \\
\hline
\end{tabular}

The average effectiveness of a factor is calculated by dividing the sum of the test results containing the factor by the number of tests performed at the same level (Equation 2 is example for pulse current, level1).

$$
<\mathrm{S} / \mathrm{N}\rangle_{\mathrm{A} 1}=\left(\mathrm{S} / \mathrm{N}_{1}+\mathrm{S} / \mathrm{N}_{2}+\mathrm{S} / \mathrm{N}_{3}\right) / 3
$$

The same procedure is applied to calculate the average signal-to-noise ratio for each parameter at all levels (Table 4).

Table 4. Calculation of the (average $\mathrm{S} / \mathrm{N})^{*}$ ratio for each level

\begin{tabular}{|c|c|c|c|c|}
\hline Parameters & Notation & Level 1 & Level 2 & Level 3 \\
\hline$I_{\text {pulse }}(\mathrm{A})$ & A & $\langle\mathrm{S} / \mathrm{N}\rangle_{\mathrm{A} 1}=\left(\mathrm{S} / \mathrm{N}_{1}+\mathrm{S} / \mathrm{N}_{2}+\mathrm{S} / \mathrm{N}_{3}\right) / 3$ & $\langle\mathrm{~S} / \mathrm{N}\rangle_{\mathrm{A}_{2}}=\left(\mathrm{S} / \mathrm{N}_{4}+\mathrm{S} / \mathrm{N}_{5}+\mathrm{S} / \mathrm{N}_{6}\right) / 3$ & $\langle\mathrm{~S} / \mathrm{N}\rangle_{\mathrm{A} 3}=\left(\mathrm{S} / \mathrm{N}_{7}+\mathrm{S} / \mathrm{N}_{8}+\mathrm{S} / \mathrm{N}_{9}\right) / 3$ \\
\hline$I_{\text {pause }}(A)$ & B & $\langle\mathrm{S} / \mathrm{N}\rangle_{\mathrm{B} 1}=\left(\mathrm{S} / \mathrm{N}_{1}+\mathrm{S} / \mathrm{N}_{4}+\mathrm{S} / \mathrm{N}_{7}\right) / 3$ & $\langle\mathrm{~S} / \mathrm{N}\rangle_{\mathrm{B} 2}=\left(\mathrm{S} / \mathrm{N}_{2}+\mathrm{S} / \mathrm{N}_{5}+\mathrm{S} / \mathrm{N}_{8}\right) / 3$ & $\langle\mathrm{~S} / \mathrm{N}\rangle_{\mathrm{B} 3}=\left(\mathrm{S} / \mathrm{N}_{3}+\mathrm{S} / \mathrm{N}_{6}+\mathrm{S} / \mathrm{N}_{9}\right) / 3$ \\
\hline $\mathbf{f}(\mathrm{Hz})$ & C & $<\mathrm{S} / \mathrm{N}>_{\mathrm{C} 1}=\left(\mathrm{S} / \mathrm{N}_{1}+\mathrm{S} / \mathrm{N}_{6}+\mathrm{S} / \mathrm{N}_{8}\right) / 3$ & $\langle\mathrm{~S} / \mathrm{N}\rangle_{\mathrm{C} 2}=\left(\mathrm{S} / \mathrm{N}_{2}+\mathrm{S} / \mathrm{N}_{4}+\mathrm{S} / \mathrm{N}_{9}\right) / 3$ & $<\mathrm{S} / \mathrm{N}>_{\mathrm{C} 3}=\left(\mathrm{S} / \mathrm{N}_{3}+\mathrm{S} / \mathrm{N}_{5}+\mathrm{S} / \mathrm{N}_{7}\right) / 3$ \\
\hline PT (\%) & D & $\langle\mathrm{S} / \mathrm{N}\rangle_{\mathrm{D} 1}=\left(\mathrm{S} / \mathrm{N}_{1}+\mathrm{S} / \mathrm{N}_{5}+\mathrm{S} / \mathrm{N}_{9}\right) / 3$ & $\langle\mathrm{~S} / \mathrm{N}\rangle_{\mathrm{D} 2}=\left(\mathrm{S} / \mathrm{N}_{2}+\mathrm{S} / \mathrm{N}_{6}+\mathrm{S} / \mathrm{N}_{7}\right) / 3$ & $\langle\mathrm{~S} / \mathrm{N}\rangle_{\mathrm{D} 3}=\left(\mathrm{S} / \mathrm{N}_{3}+\mathrm{S} / \mathrm{N}_{4}+\mathrm{S} / \mathrm{N}_{8}\right) / 3$ \\
\hline
\end{tabular}

Also, for each parameter, the average $S / N$ difference, that is, the maximum minus minimum value (Delta), is calculated. These results are then ranked (Table $5.1,5.2,5.3)$. The pulse current for the penetration depth (PD) parameter is ranked as "1", as shown in Table 5.1, indicating that its effect is more significant for increasing (and vice versa) PD than other parameters such as pause current, pulse on time, and frequency. The picture is similar for parameters such as the SW and HAZ, where the maximum contribution is made by the pulse current. Notably, the other welding parameters ( $I_{\text {pause }}, f, P T$ ) have different influences on the weld geometry (WG). Based on the resultant average $S / N$ for each level, it becomes possible to set the required welding mode. This means that for achieving a minimal $\mathrm{PD}$, a minimal level (corresponding to the minimum of the average $S / N$ response) must be taken for each welding parameter. Specifically, it will be "level 1" for "I pulse", "level 1" for "Ipause", "level 1" for "f" and "level 1" for "PT", and so on. 
Table 5.1 Details of average S/N Response PD

Parameters Notation Level 1 Level 2 Level 3 Delta $(\Delta)$ Rank

\begin{tabular}{c|cccccc}
$I_{\text {pulse }}(A)$ & A & 4.47 & 9.11 & 10.3 & 5.85 & 1 \\
$I_{\text {pause }}(A)$ & B & 6.25 & 9.39 & 8.24 & 3.15 & 4 \\
$f(H z)$ & C & 5.45 & 9.24 & 9.19 & 3.79 & 2 \\
$P T(\%)$ & D & 6.59 & 7.46 & 9.84 & 3.25 & 3
\end{tabular}

Table 5.2 Details of average S/N Response SW

Parameters Notation Level 1 Level 2 Level 3 Delta( $(\Delta)$ Rank

\begin{tabular}{c|cccccc}
$I_{\text {pulse }}(A)$ & A & 21.48 & 22.73 & 23.99 & 2.5 & 1 \\
$I_{\text {pause }}(A)$ & B & 22.53 & 23.1 & 22.57 & 0.58 & 3 \\
$f(H z)$ & C & 22.52 & 22.82 & 22.85 & 0.33 & 4 \\
$P T(\%)$ & D & 22.35 & 22.32 & 23.53 & 1.22 & 2
\end{tabular}

Table 5.3 Details of average S/N Response HAZ

Parameters Notation Level 1 Level 2 Level 3 Delta( $\Delta)$ Rank

\begin{tabular}{c|cccccc}
\hline$I_{\text {pulse }}(A)$ & A & 4.28 & 2.76 & 5.64 & $\mathbf{2 . 8 8}$ & 2 \\
$I_{\text {pause }}(A)$ & B & 3.74 & 3.72 & 5.21 & $\mathbf{1 . 4 9}$ & 3 \\
$f(H z)$ & C & 6.27 & 3.11 & 3.29 & 3.16 & 1 \\
$P T(\%)$ & D & 3.89 & 4.68 & 4.11 & $\mathbf{0 . 7 9}$ & 4
\end{tabular}

Nominal control of the final response requires knowledge of the contribution of individual process parameters, which can be estimated using a statistical method, namely ANOVA [23]. In ANOVA methodology, SS, SS ', D, V, and P are typical parameter symbols used in the above analysis to represent factors, sum and adjusted sum of squares, degrees of freedom, variance, and percentage contribution. Each factor is passed through individually. A brief explanation of the above factors is presented below [25]: 
The total sum of squares SST can be calculated from the S/N ratio using Equation 3, which uses the terms "total number of experiments $(m=9)$ " and "i-th, the current signal-to-noise ratio $\eta_{i}{ }^{\prime \prime}$

$$
S S_{T}=\sum_{i=1}^{9} S / N_{i}^{2}-\frac{1}{9} \cdot\left(\sum_{i=1}^{9} S / N_{i}\right)^{2}
$$

The sum of the squares of the factors denoted by $S S p$ is calculated by Equation 4 with the following conditions: the factor "p" and its level number as "j", repetition of each level for the tested factor $\mathrm{p}$ as ' $\mathrm{t}$ ' (=3), summation signal-to-noise ratio $(\mathrm{S} / \mathrm{N})$ connecting this coefficient $\mathrm{p}$ and its level $\mathrm{j}$ as $\mathrm{S} / \mathrm{Npj}=\left(\mathrm{S} / \mathrm{N}_{1}+\mathrm{S} / \mathrm{N}_{2}+\mathrm{S} / \mathrm{N}_{3}\right)$ for level $A_{j=1} ;\left(S / N_{2}+S / N_{3}+S / N_{4}\right)$ for level $A_{j=2} ;\left(S / N_{7}+S / N_{8}+S / N_{9}\right)$ for level $A_{j=}$

$$
S S_{P}=\sum_{j=1}^{3} \frac{\left(\sum S / N p j\right)^{2}}{3}-\frac{1}{9} \cdot\left(\sum_{i=1}^{9} S / N_{i}\right)^{2}
$$

Degree of freedom (DOF) is one of the elements to consider when calculating ANOVA. Dp and $V p$ are notations used to represent the degrees of freedom and variance of factor $p . V p$ is determined as a percentage using the Dp and SSp according to Equation 5.

$$
V_{p}(\%)=\frac{S S_{P}}{D_{P}} \times 100
$$

The summation of the DOFs, followed by a series of tests and averages, is called the total DOF. The degree of freedom for the mean is always 1 . Therefore, the total degree of freedom for this experimental study is 8 , which is equal to the number of trials (9 trials) minus 1 , and the degree of freedom for the parameters is 2 , obtained by subtracting 1 from the number of parameter levels (3 levels).

The difference between SSp (sum of squared factors) and the product of the error variance and DOF of each test factor is called the corrected sum of squares 
and is referred to as SS'p, which is calculated using Equation 6 (where Ve experimental).

$$
S S_{P}{ }^{\prime}=S S_{P}-D_{P} V_{e}
$$

The percentage of the factors tested between their corrected sum and the total sum of squares is called their percentage contribution and is denoted as Pp. Equation 7 is used to determine $\mathrm{Pp}$.

$$
P_{p}(\%)=\frac{S S_{P}^{\prime}}{S S_{T}} \times 100
$$

Summarized results of the quantitative input of each welding parameter to the formation of the weld geometry are presented in figure 4 .

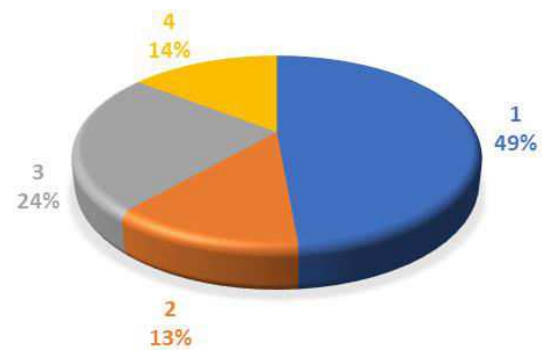

a)

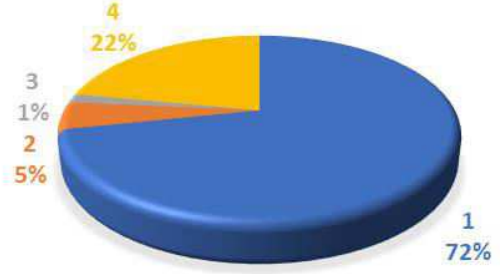

b)

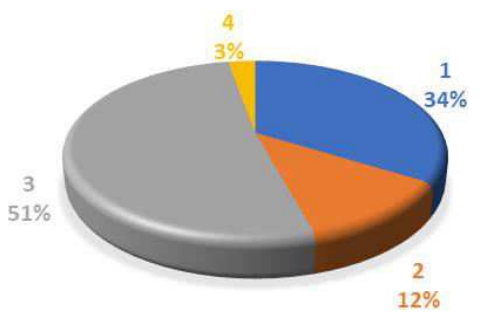

c)

Figure 4. Quantitative input of welding parameters into the weld geometry. $a-P D, b$ - SW, c - HAZ; 1 - I $I_{\text {pulse }}(A), 2$ - I pause (A), 3 - $f(H z), 4$ - PT (\%)

After selecting the optimum level of design parameters, it is a mandatory step to identify and verify the improvement in quality performance using the optimal level of design parameters. According to references $[23,25,26]$, the predicted signal-tonoise ratio for the optimal level of the design process parameters can be calculated as: 


$$
\eta=\eta_{m}+\sum_{i=1}^{n}\left(\bar{\eta}_{i}-\eta_{m}\right)
$$

In the above equation, $\mathrm{m}, \mathrm{i}$, and $\mathrm{n}$ represent the overall average signal-tonoise ratio; the optimal level of the average signal-to-noise ratio (see Table 5) and the total number of important designs of experimental parameters affecting the quality, respectively. The predicted $\mathrm{S} / \mathrm{N}$ ratio can be found using the optimal PAGMAW designed process parameters.

Base on the calculations of the average $S / N$ ratio for each level and parameter presented in Table 5.1-5.3, it becomes possible to set up optimal welding mode for achieving desire welds geometry. For instance, to achieve minimal penetration depth we should use that level that corresponds to the minimal value of the average $\mathrm{S} / \mathrm{N}$ ratio for each welding parameter. According to this algorithm for minimal PD it should be taken level1 for Ipulse, level 1 for Ipause, level 1 for frequency, and level 1 for pulse on time. A similar routine has been made for other welds geometry parameters i.e for HAZ and SW. These developed optimal welding modes are presented in table 6.1-6.3, as well as the predicted $S / N$ ratio for measured welds geometry parameter and its experimental verification.

Table 6.1 Predicted and confirmation test results for optimal mode of the PA-GMAW process (PD min).

\begin{tabular}{|c|c|c|c|c|c|c|}
\hline \multirow{3}{*}{ Parameters } & A & B & C & D & \multicolumn{2}{|c|}{ (S/N Ratio)/Value } \\
\hline & \multirow{2}{*}{$\begin{array}{l}I_{\text {pulse }} \\
\text { (A) }\end{array}$} & \multirow{2}{*}{$\begin{array}{l}I_{\text {pause }} \\
\text { (A) }\end{array}$} & \multirow[t]{2}{*}{$f(H z)$} & \multirow{2}{*}{$\begin{array}{l}\text { PT } \\
(\%)\end{array}$} & & \\
\hline & & & & & Prediction & Experiment \\
\hline Optimum coded value & 1 & 1 & 1 & 1 & & \\
\hline Optimum original value & 160 & 80 & 0.5 & 40 & $-1.1 / 0.80$ & $-1.27 / 0.8 /$ \\
\hline
\end{tabular}

Table 6.2 Predicted and confirmation test results for the optimal mode of the PAGMAW process (HAZ min)

\begin{tabular}{|c|c|c|c|c|c|}
\hline \multirow{3}{*}{ Parameters } & A & B & C & D & \multirow[t]{2}{*}{ (S/N Ratio)/Value } \\
\hline & $I_{\text {pulse }}$ & $I_{\text {pause }}$ & $f(H z)$ & PT & \\
\hline & (A) & (A) & & $(\%)$ & Prediction Experiment \\
\hline
\end{tabular}




\begin{tabular}{lllllll}
\hline Optimum coded value & 2 & 2 & 2 & 1 & \multirow{2}{*}{$0.8 / 1.09$} & $0.87 / 1.10$ \\
\hline Optimum original value & 200 & 120 & 1 & 40 & & \\
\hline
\end{tabular}

Table 6.3 Predicted and confirmation test results for the optimal mode of the PAGMAW process (SW max)

\begin{tabular}{|c|c|c|c|c|c|c|}
\hline \multirow{3}{*}{ Parameters } & A & B & C & $\mathbf{D}$ & \multicolumn{2}{|c|}{ S/N Ratio/Value } \\
\hline & $I_{\text {pulse }}$ & $I_{\text {pause }}$ & $f(H z)$ & $\mathrm{PT}$ & & \\
\hline & (A) & (A) & & $(\%)$ & Prediction & Experiment \\
\hline Optimum coded value & 3 & 2 & 3 & 3 & \multirow{2}{*}{ 25.3/18.4 } & \multirow{2}{*}{ 26/19.9 } \\
\hline Optimum original value & 240 & 120 & 5 & 80 & & \\
\hline
\end{tabular}

From achieved results, it is clearly seen that the prediction of the weld geometry parameters (PD, HAZ, SW) are in a good agreement with experimental results. In particular, for $\mathrm{PD} S / \mathrm{N}$ prediction is -1.10 , and experimental results give 1.21 which corresponds to PD equal to $0.88 \mathrm{~mm}$ (prediction) and $0.87 \mathrm{~mm}$ (experimental) respectively.

\subsection{Building of the modeling wall}

For further experimentation with the WAAM model wall building, it is recommended to choose the PA-GMAW welding mode that provides the minimal $P D$. That selection is grounded to minimize the effect of the currently deposited layer on the previous one. The mode that provides the maximum SW is more suitable for surfacing instead of wall construction, and the mode that provides minimum HAZ for ferritic-pearlitic steels. To demonstrate the benefits of the proposed welding mode, the standard PC-GMAW mode with the same average welding current was chosen (Table 7).

Table 7. Welding modes for wall construction.

\begin{tabular}{|l|l|l|l|}
\hline Welding mode & Welding Current, A & Welding Voltage, V & $\begin{array}{l}\text { Welding Speed, } \\
\mathrm{m} / \mathrm{h}\end{array}$ \\
\hline
\end{tabular}




\begin{tabular}{|l|l|l|l|}
\hline PA-GMAW & $118^{*}$ & 18.7 & 15 \\
\hline PC-GMAW & 118 & 18.7 & 15 \\
\hline${ }^{*}-$ here average current is calculated with I= $\left(\right.$ I $\left._{\text {pulse }}{ }^{*} \mathrm{t}_{\text {pulse }}+\mathrm{I}_{\text {pause }}{ }^{*} \mathrm{t}_{\text {pause }}\right) /\left(\mathrm{t}_{\text {pulse }}+\mathrm{t}_{\text {pause }}\right)=\left(160^{*} 0.8+80^{*} 1.2\right) /(0.8+1.2)$ \\
\hline
\end{tabular}

The deposited layers marked in (Figure 5) are divided into classes - buffer layers $(1,2)$, cover layer $(5)$, and representative layers $(3,4)$. From the obtained experimental results, it is clearly seen that PA-GMAW forms sharper walls with edged side surfaces. Furthermore, it is clearly seen that the PA-GMAW provides more sound formation of the wall. PC-GMAW has wave shape transition from layer to layer. This advantage of PA-GMAW leads to less further machining treatment of the surface if needed. To demonstrate the quality of the metal deposited on this model wall, it is necessary to consider the microstructure as well as the mechanical properties.
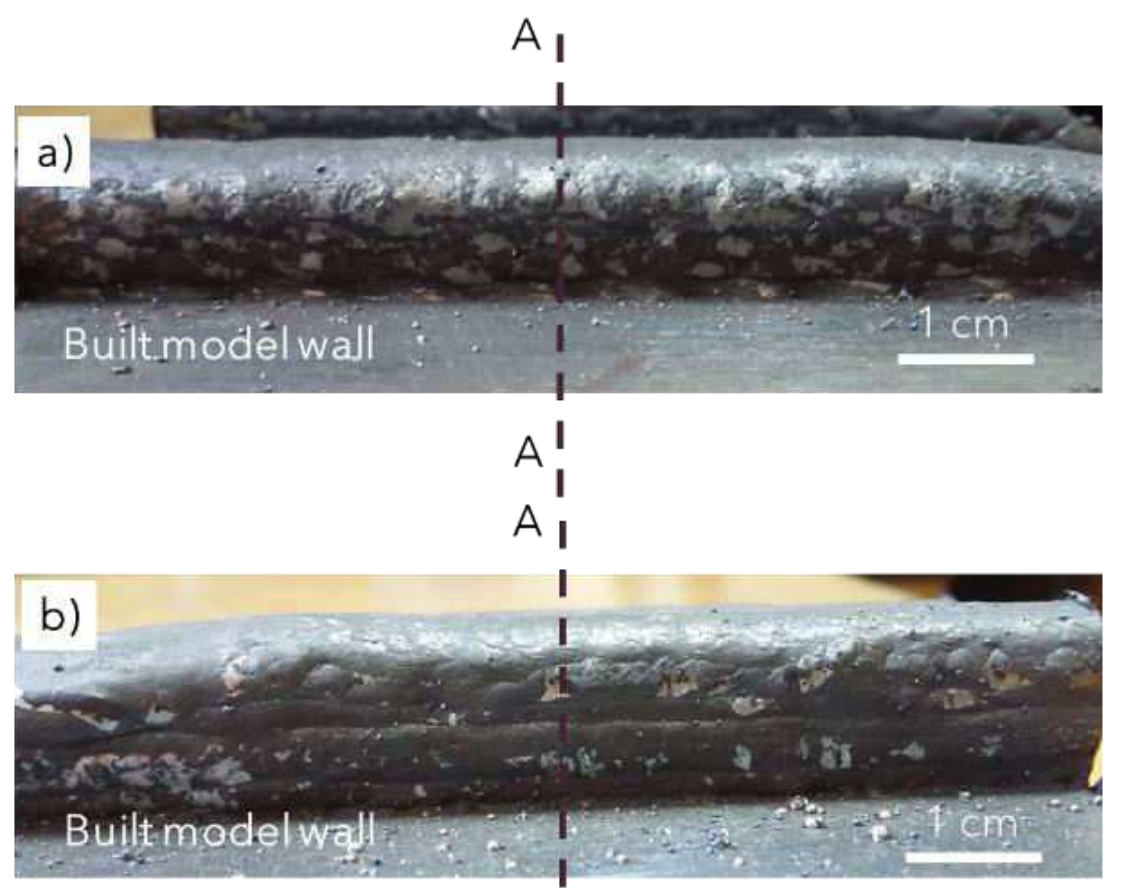

$$
\text { A ! }
$$
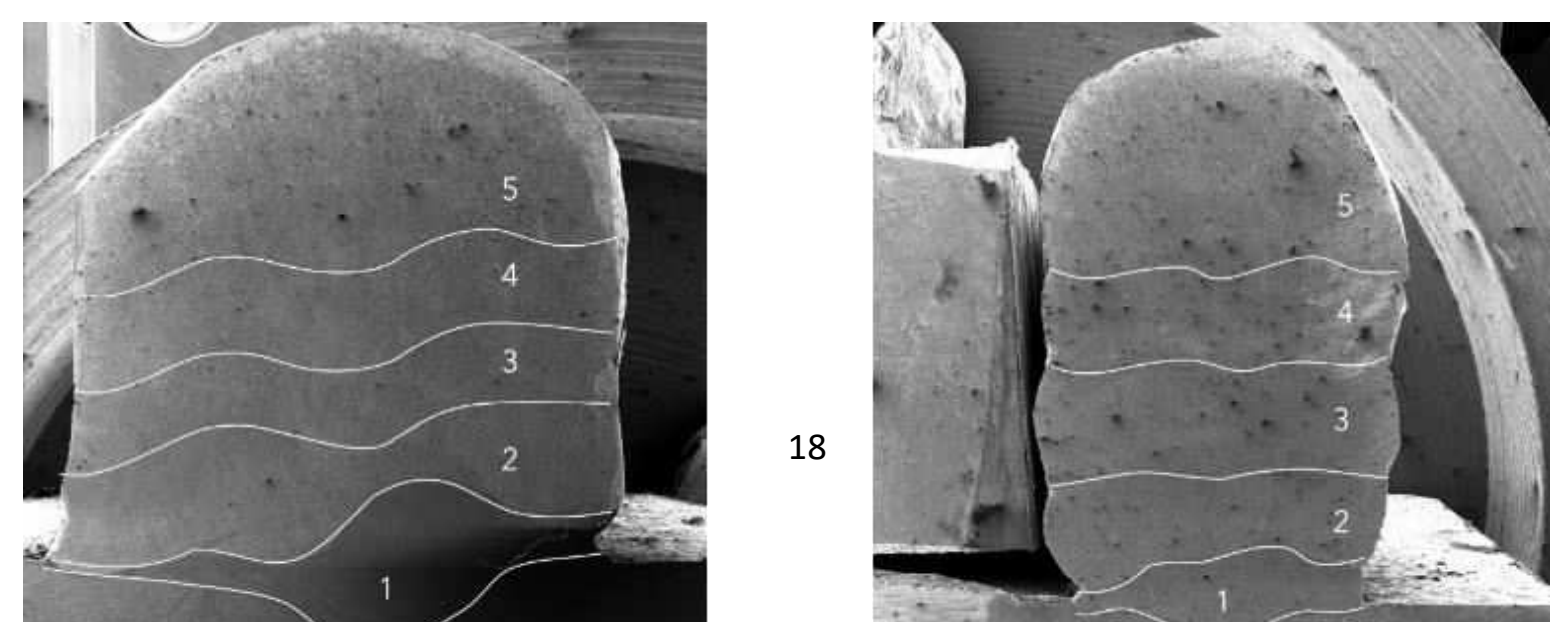
Figure 5. General view $(a, b)$ and cross-section macrostructure $(c, d)$ of the modelled wall. a,c - PA-GMAW; b,d- PC-GMAW

Since the welding modes were chosen, it is essential to consider the welding thermal cycle (WTC) of the modes. WTC determines the kinetic of further structure formation and, accordingly, the properties of the final product. The PA-GMAW (Figure 6) allows lower cooling rates to achieve in the $600-500{ }^{\circ} \mathrm{C}$ temperature range, while it is comparable to the $\mathrm{PC}-\mathrm{GMAW}$ in the high temperature range. This fact has a positive effect on the deposited metal in the sense of reducing residual stresses and favorable conditions for structure formation.

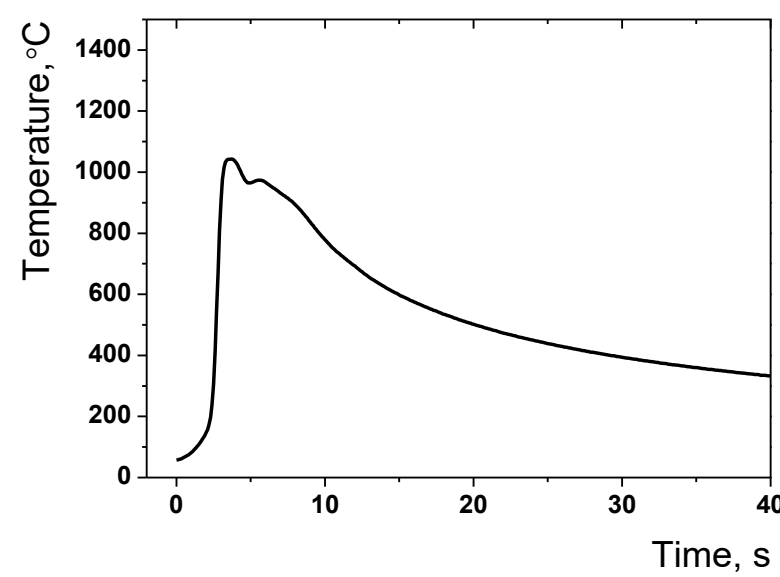

a)

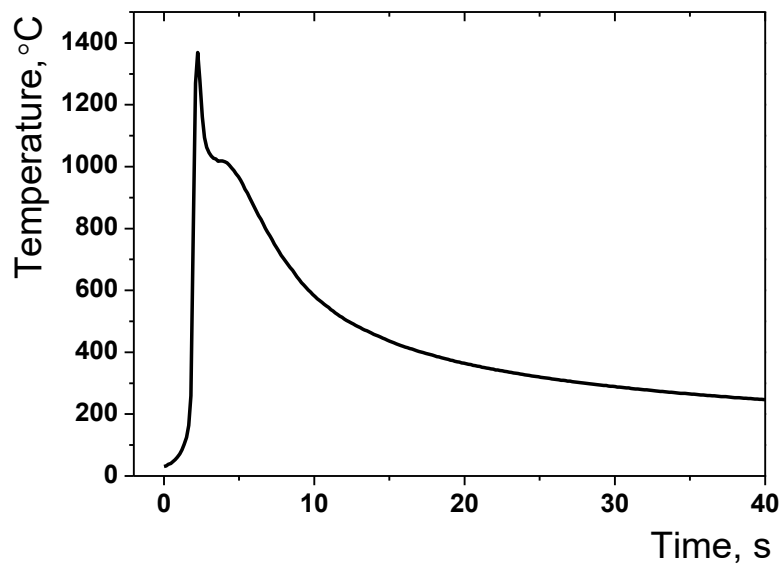

b) 
Figure 6. Welding thermal cycles for PA-GMAW (a) and PC-GMAW (b)

To demonstrate the quality of the metal deposited on this model wall, it is necessary to consider the microstructure as well as the mechanical properties.

\subsection{Structure and mechanical properties of the modelled walls}

Just like the model wall, there are 5 layers, the first one is the buffer layer. In the buffer layer, active mixing of the deposited metal and substrate occurs. Thus, it should be excluded from consideration of the microstructure. The second one also has chemical inhomogeneities due to possible mixing with the previous layer.

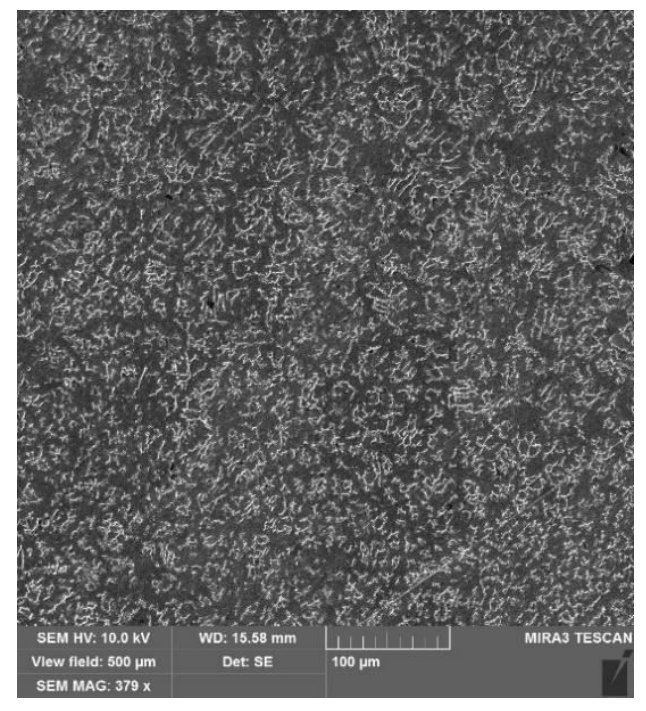

a)

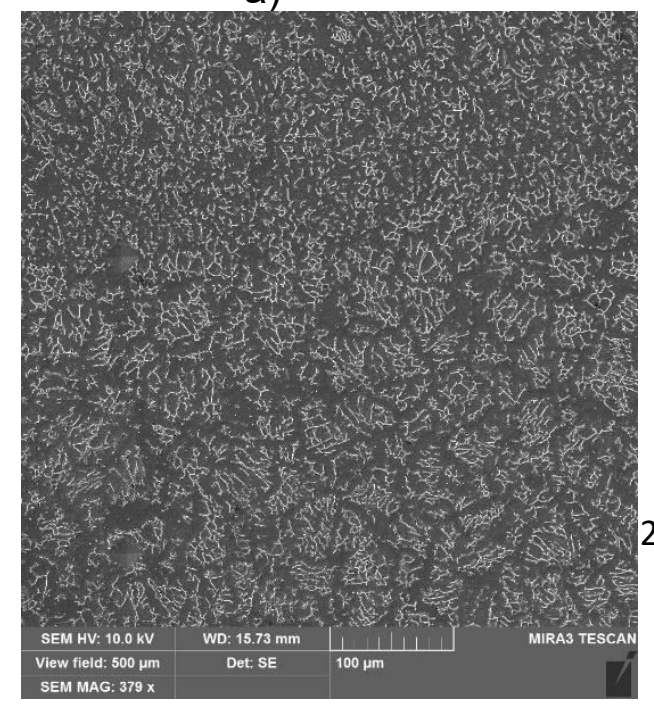

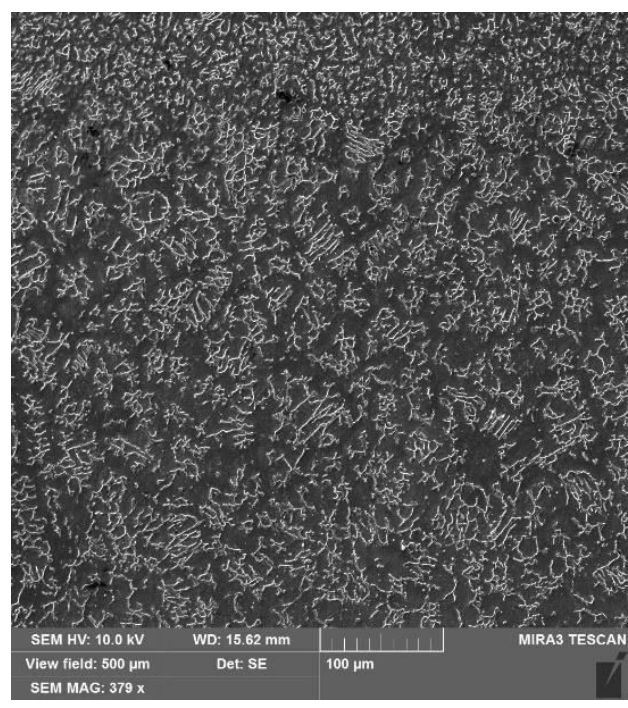

b)

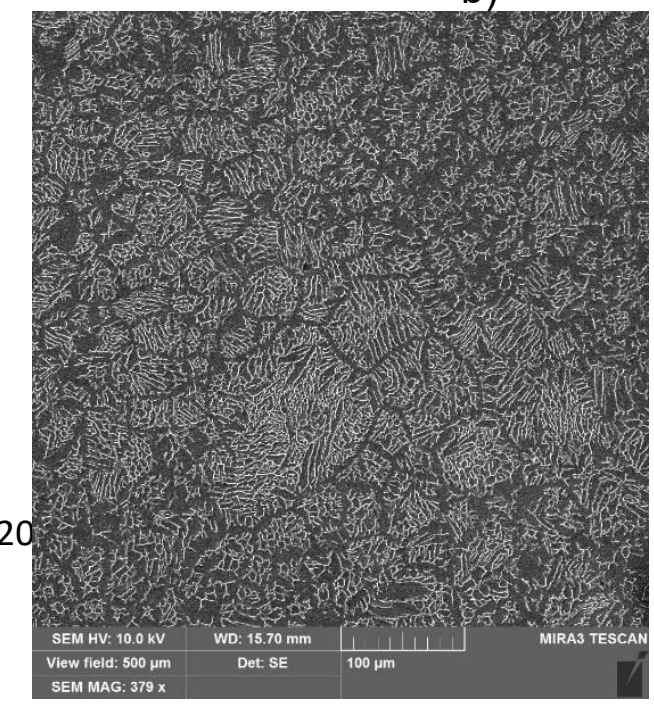


c)

d)

Figure 7. SEM microstructure of the representative layers $3(a, c)$ and 4 (b,d). a,b PA-GMAW, c, d -PC-GMAW

Therefore, to clearly understand the welding mode effect, it is reasonable to consider the $3^{\text {rd }}$ layer. The last one, i.e., the $5^{\text {th }}$ layer should also be excluded from the analysis on the basis that this is a cover layer, and it will be removed in further treatment, as usual. In this regard, the detailed attention attracts exactly to the $3^{\text {rd }}$ and $4^{\text {th }}$ layers. The microstructure of these layers, etched to reveal the delta-phase (delta-ferrite), is shown in figure 7.

The following is clear evidence of the homogeneity of the structure for the PAGMAW welding mode. First, the average size of the delta ferrite colonies in representative layers is equal to 21 and $29 \mu \mathrm{m}$ for layers 3 and 4 , respectively. In contrast, the same regions for the PC-GMAW welding mode show much higher values, i.e., 46 and $73 \mu \mathrm{m}$, respectively.

Second, the EDS spectra of the distribution of the alloying elements also have shown better results in the PA-GMAW welding mode. For EDS spectra, it is reasonable to show the distribution of the II-III, III-IV-, IV-V layers, where this will be the representative volume of the modeled wall. The analysis has chosen good uniformity of distribution of chemical elements in selected representative volumes (figure 8). 
|I-III

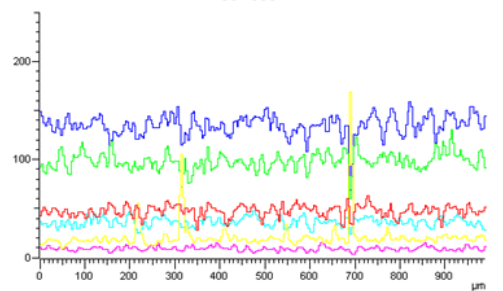

(Ni) $\mathrm{Fe} \mathrm{Mn}$

(Cr) $\mathrm{Ti}$ (Si a)

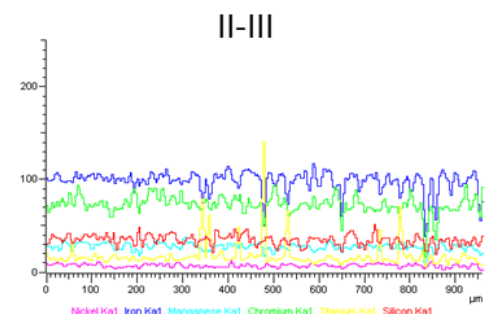

(Ni) $\mathrm{Fe} M$ (Cr $\mathrm{Ti}$ (Si

d)
III-IV

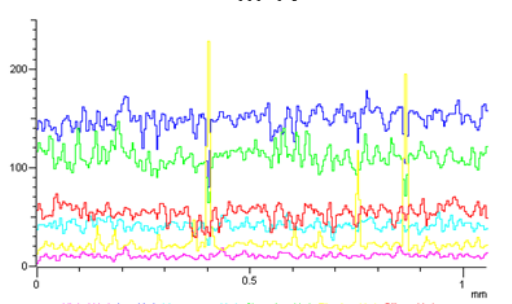

(Ni) $\mathrm{Fe} \mathrm{Mn}$

(Si) b)

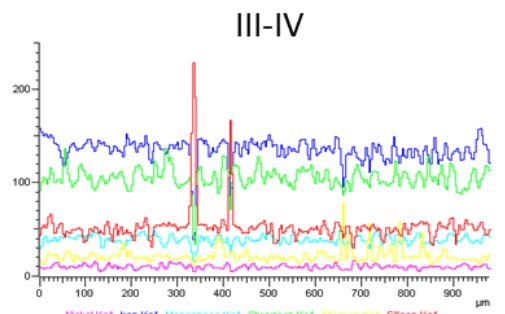

(Ni) $\mathrm{Fe}(\mathrm{Mn}$ (Cr) $\mathrm{Ti}$ (Si

e)
IV-V

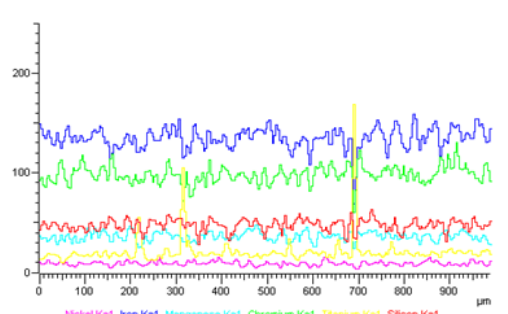

(Ni) $\mathrm{Fe}$ (Mn (Cr) Ti (Si)

c)

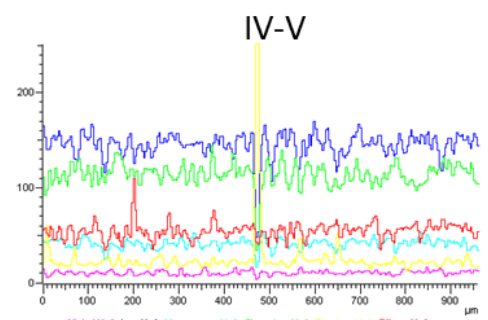

(Ni) $\mathrm{Fe}$ Mn $\mathrm{Cr}$ Ti $\mathrm{Si}$

Figure 8. EDS spectra of main alloying elements distribution in deposited metal for PA-GMAW (a-c), and PC-GMAW (d-f).

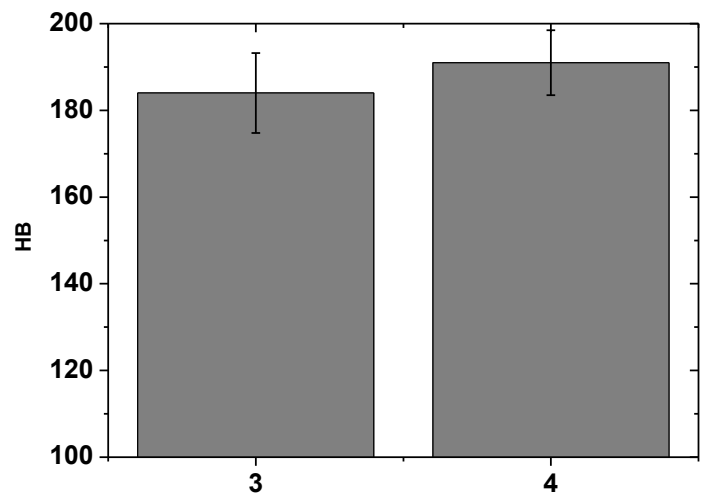

a)

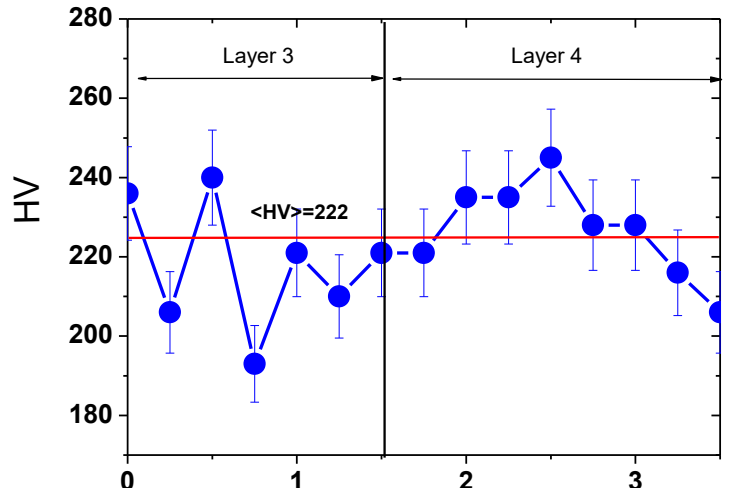

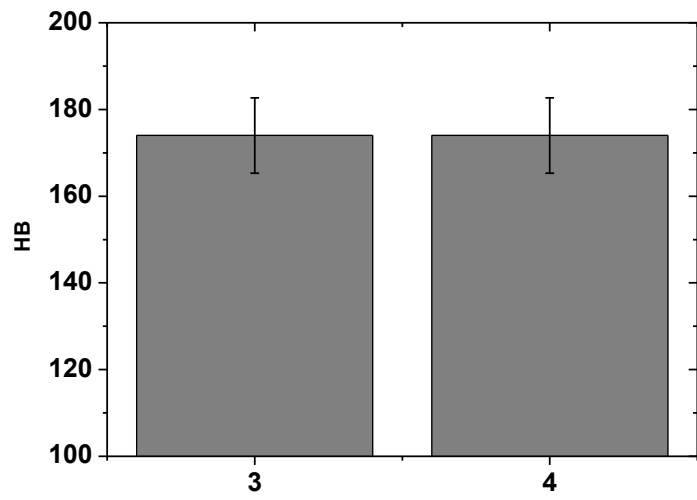

b)

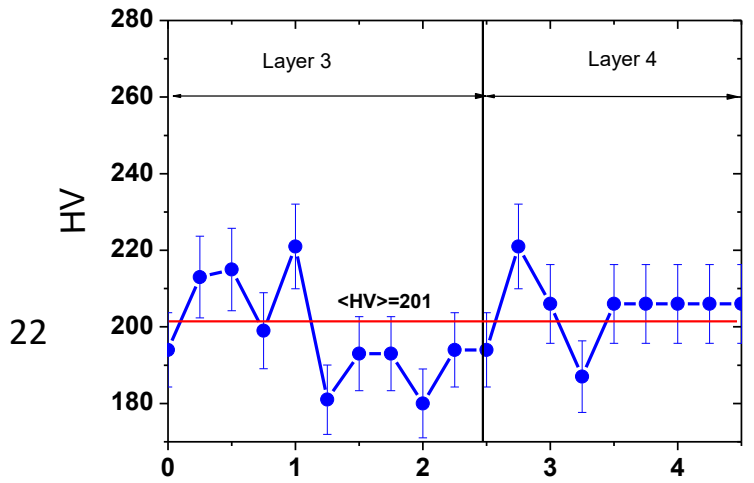


c)

d)

Figure 9. Hardness distribution for representative layers 3, 4. a,b-Brinell, c,d - Vickers. a,c - PA-GMAW, b,d - PC-GMAW

Hardness and microhardness provide an opportunity to estimate the homogeneity of the distribution of properties. HB reflects the macroscopic characteristics and HV - micro and imprint size is around $20 \mu$. It is clearly seen that the hardness of PA-GMAW at micro and macro levels has higher values compared to PC-GMAW (figure 9). These features are explained by the structure.

From Figure 10, regarding the represented structure of the $4^{\text {th }}$ (representative) layer, it is clearly seen that with PA-GMAW the structure is more fine-grained instead of PC-GMAW.

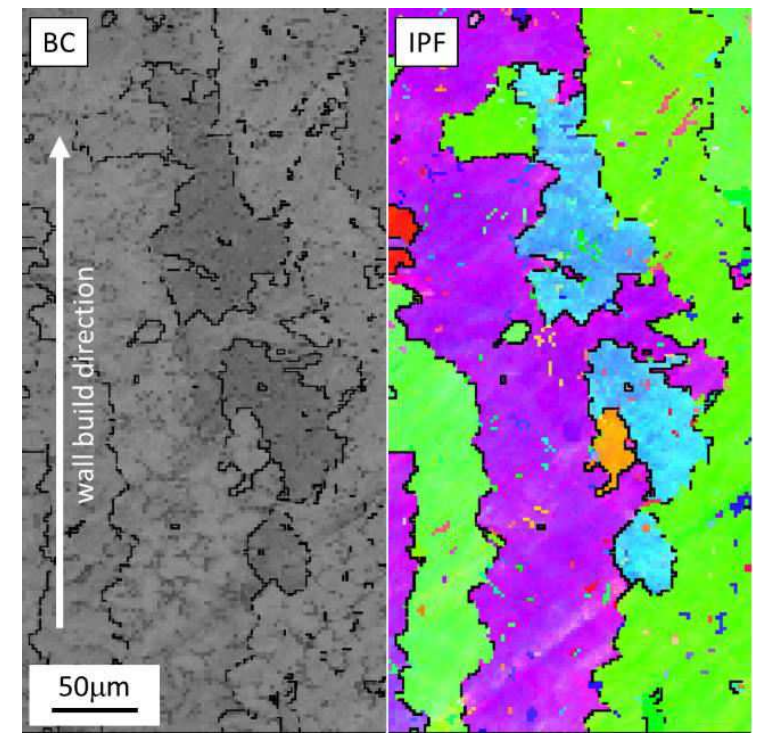

a)

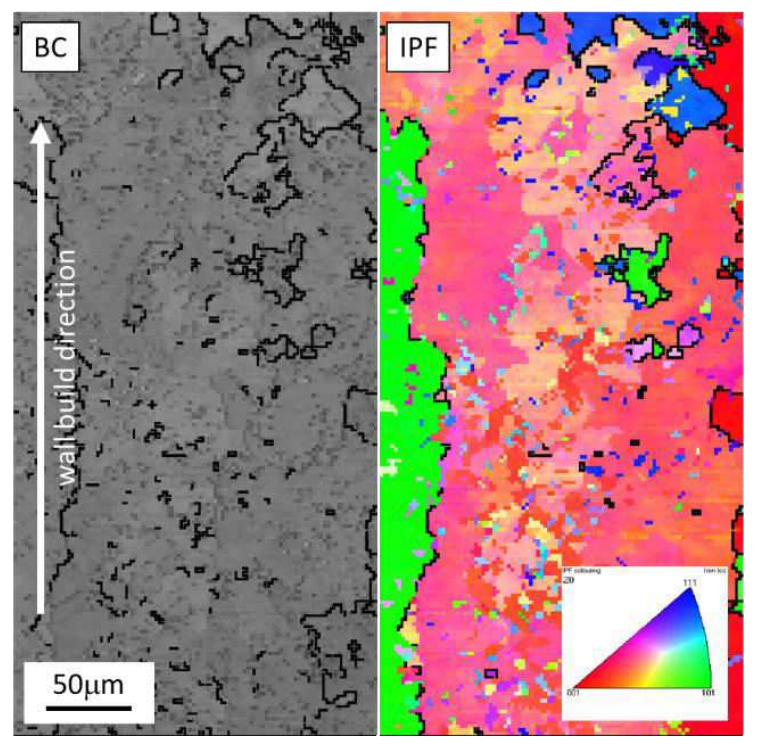

b) 
Figure 10. EBSD band contrast and IPF maps ( $Z$ direction) of the representative layer 4. a - PA-GMAW, b -PC-GMAW

The mechanical tensile tests have shown that the structural peculiarities provide a higher level of strength. In particular, YS for PA-GMAW is $100 \mathrm{MPa}$ higher than that of PC-GMAW at the same level of plasticity and UTS (figure 11).

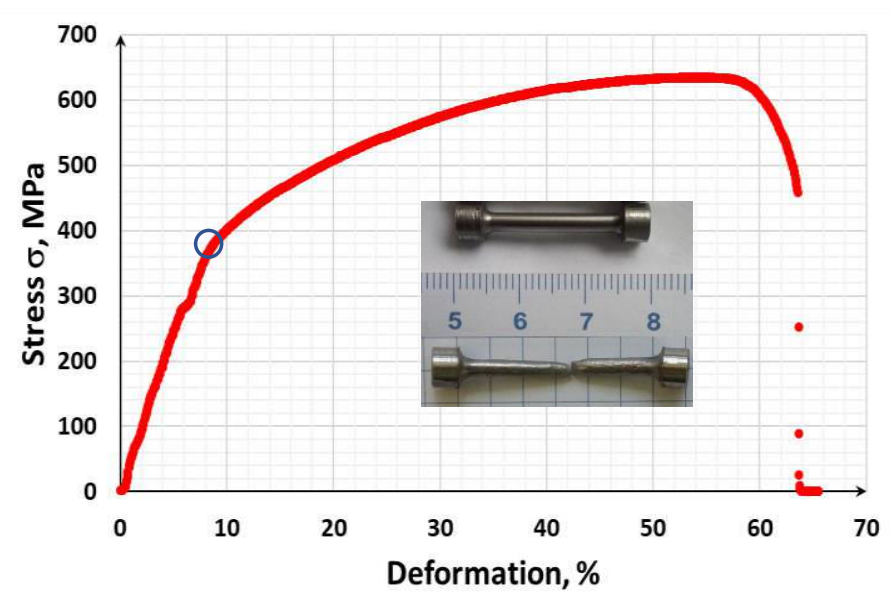

a)

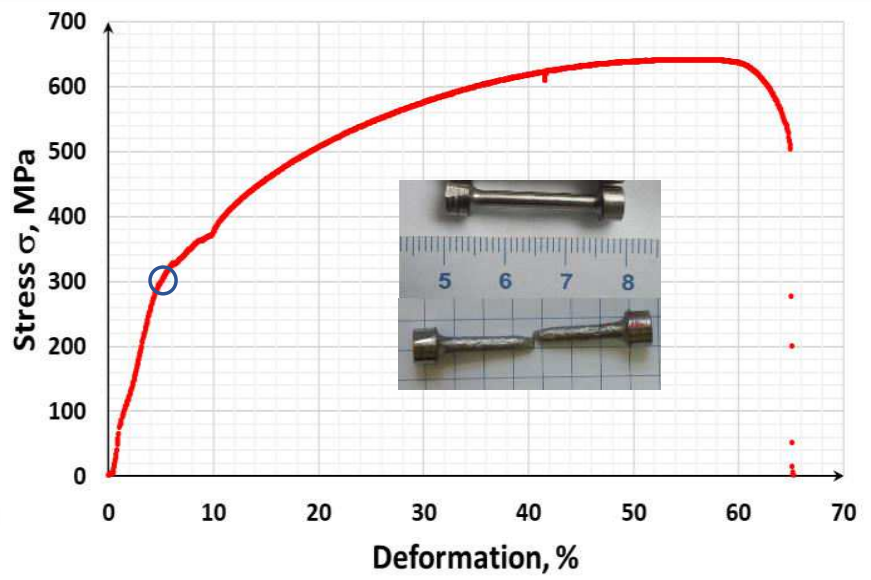

b)

Figure 11. Tensile test of the modeled wall. a - PA-GMAW, b-PC-GMAW
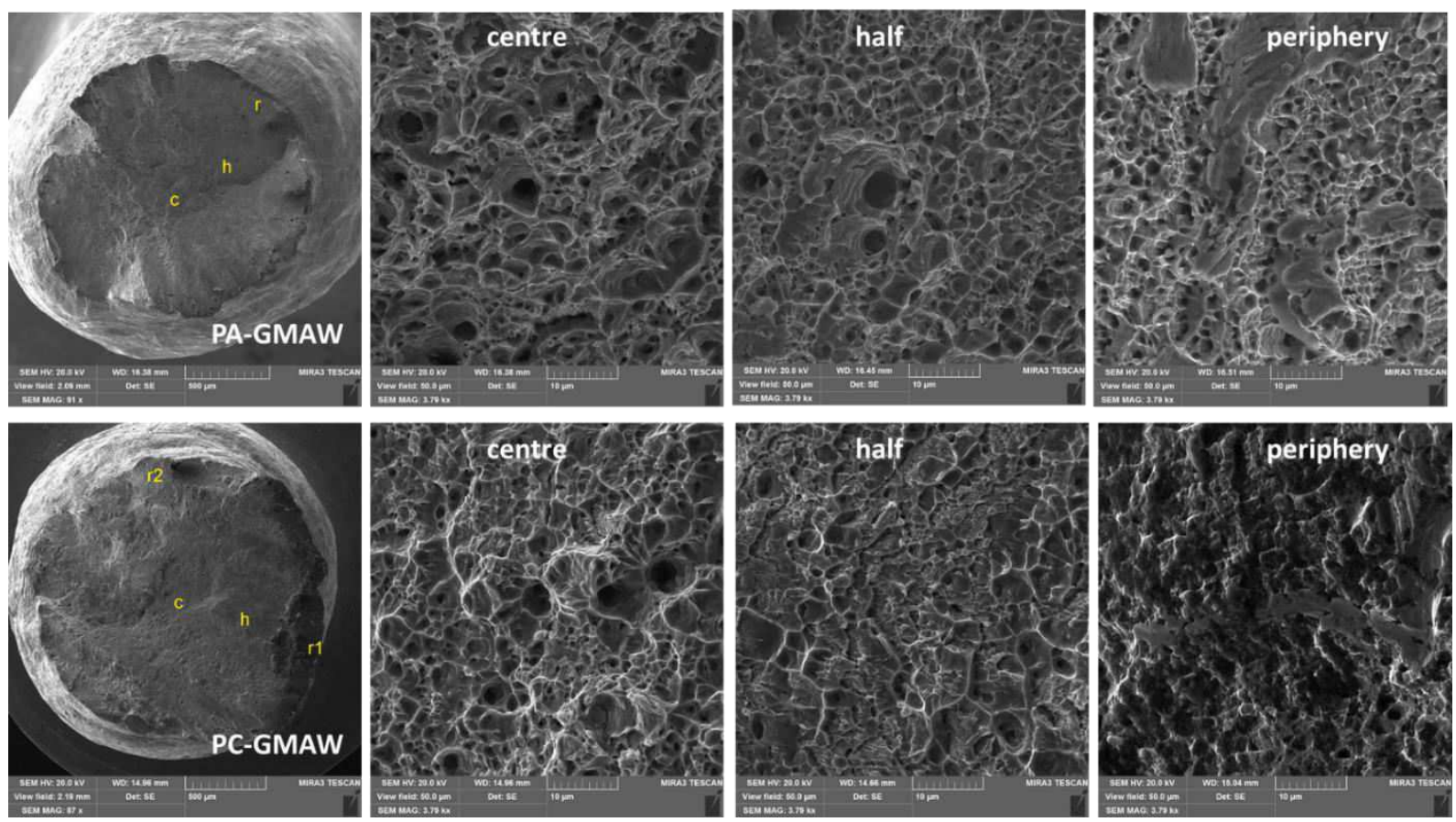
Figure 12. Fracture surface for representative layer 4, tensile test. PA-GMAW upper row, PC-GMAW - lower row

The fractography investigations revealed that both samples have ductile nature of fracture, but the PA-GMAW has a slightly higher energy capacity than PCGMAW samples because it has a larger facet (figure 12).

Therefore, the analysis of various sites, from microstructure to properties, demonstrated the benefits of the developed PA-GMAW welding mode for WAAM purpose.

\section{Conclusion}

The design of the experimental possibilities has been successfully performed to develop optimized welding modes for wire arc additive manufacturing purposes. Based on the model material of austenitic composition, the advantages of the proposed welding modes were shown. In particular, PA-GMAW with developed mode provides:

- Sound formation of the deposited metal with a decreased spattering

- Higher micro and microhardness

- Fine grained structure

- Higher strength with compared plasticity

Therefore, the design of the experiment with the Taguchi algorithm can be successfully applied to the development of WAAM operating modes.

\section{Novelty}

- The application of the Taguchi algorithm demonstrates a cost-effective alternative to machine learning (ex.) that requires a lot of experiments.

- The application of austenitic materials highlighted the pure effect of prognoses welding mode. 
- For wire arc additive manufacturing, it is proposed to use PA-GMAW (lowfrequency pulses) to improve the whole process.

- As advantages of using PA-GMAW, the sound formation of the weld, geometry, quality of seam, final structure finish, and mechanical properties are better.

- Not only is the simple usage of GMAW good for WAAM, but it also shows the programming/prognoses of special modes to improve the design of WAAM technologies.

\section{Contributor Roles Taxonomy}

Anatoliy Zavdoveev, Thierry Baudin, Hyoung Seop Kim and Philippe Aquier Conceptualization, Methodology Anatoliy Zavdoveev, Valeriy Poznyakov Supervision llya Klochkov, Sviatoslav Motrunich, Massimo Rogante, Anatoliy Denisenko, Alex Gajvoronskiy, Mykola Skoryk and Mark Heaton Data curation, Writing- Original draft preparation. All authors discussed the results and commented on the manuscript.

\section{Acknowledgments}

This work was supported by the National Academy of Sciences of Ukraine [grant number 0117U001666] and National Research Foundation of Korea (NRF) grant funded by the Korea government (MSIP) (NRF-2021R1A2C3006662). The authors are grateful to Prof. E. MacDonald (The University of Texas at El Paso), Dr.C.Cunningham (Metal AM - Process and Alloy development) and Dr. M. Speicher (Wissenschaftlerin bei Universität Stuttgart) for many fruitful discussions, Dr A.Shishkevich for the help in experiments.

Conflict of interest: Anatoliy Zavdoveev, Valeriy Pozniakov, Thierry Baudin, Hyoung Seop Kim, llya Klochkov, Sviatoslav Motrunich, Mark Heaton, Philippe Aquier, Massimo Rogante, Anatoliy Denisenko, Alex Gajvoronskiy, Mykola Skoryk declare that they have no conflict of interest.

Data availability: The raw/processed data required to reproduce these findings cannot be shared at this time due to technical or time limitations. 


\section{References}

[1] C.R. Cunningham, J.M. Flynn, A. Shokrani, V. Dhokia, S.T. Newman, Invited review article: Strategies and processes for high quality wire arc additive manufacturing, Addit. Manuf. 22 (2018) 672-686. https://doi.org/https://doi.org/10.1016/j.addma.2018.06.020.

[2] Y. Sun, R.J. Hebert, M. Aindow, Effect of heat treatments on microstructural evolution of additively manufactured and wrought $17-4 \mathrm{PH}$ stainless steel, Mater. Des. (2018). https://doi.org/10.1016/j.matdes.2018.07.015.

[3] J.W. Lee, H.M. Baek, S.K. Hwang, I.-H. Son, C.M. Bae, Y.-T. Im, The effect of the multi-pass non-circular drawing sequence on mechanical properties and microstructure evolution of low-carbon steel, Mater. Des. 55 (2014) 898-904. https://doi.org/10.1016/J.MATDES.2013.10.068.

[4] O. Yilmaz, A.A. Ugla, Shaped metal deposition technique in additive manufacturing: A review, Proc. Inst. Mech. Eng. Part B J. Eng. Manuf. 230 (2016) 1781-1798. https://doi.org/10.1177/0954405416640181.

[5] B. Dutta, F.H. Froes, Additive manufacturing of titanium alloys, Adv. Mater. Process. 172 (2014) 18-23. https://www.scopus.com/inward/record.uri?eid=2s2.084900592656\&partnerlD=40\&md5=0d8bc16d71c2620b1de9646c65b10f65.

[6] M.A. Jackson, A. Van Asten, J.D. Morrow, S. Min, F.E. Pfefferkorn, A Comparison of Energy Consumption in Wire-based and Powder-based Additive-subtractive Manufacturing, Procedia Manuf. 5 (2016) 989-1005. https://doi.org/https://doi.org/10.1016/j.promfg.2016.08.087.

[7] D.D. Gu, W. Meiners, K. Wissenbach, R. Poprawe, Laser additive manufacturing of metallic components: materials, processes and mechanisms, Int. Mater. Rev. 57 (2012) 133-164. https://doi.org/10.1179/1743280411Y.0000000014.

[8] J. Guo, Y. Zhou, C. Liu, Q. Wu, X. Chen, J. Lu, Wire Arc Additive 
Manufacturing of AZ31 Magnesium Alloy: Grain Refinement by Adjusting Pulse Frequency, Mater. . 9 (2016). https://doi.org/10.3390/ma9100823.

[9] S.W. Williams, F. Martina, A.C. Addison, J. Ding, G. Pardal, P. Colegrove, Wire + Arc Additive Manufacturing, Mater. Sci. Technol. 32 (2016) 641-647. https://doi.org/10.1179/1743284715Y.0000000073.

[10] D. Ding, Z. Pan, S. Van Duin, H. Li, C. Shen, Fabricating Superior NiAl Bronze Components through Wire Arc Additive Manufacturing, Mater. . 9 (2016). https://doi.org/10.3390/ma9080652.

[11] Z. Pan, D. Ding, B. Wu, D. Cuiuri, H. Li, J. Norrish, Arc Welding Processes for Additive Manufacturing: A Review BT - Transactions on Intelligent Welding Manufacturing, in: S. Chen, Y. Zhang, Z. Feng (Eds.), Springer Singapore, Singapore, 2018: pp. 3-24.

[12] M. Bruggi, V. Laghi, T. Trombetti, Simultaneous design of the topology and the build orientation of Wire-and-Arc Additively Manufactured structural elements, Comput. Struct. 242 (2021) 106370. https://doi.org/https://doi.org/10.1016/j.compstruc.2020.106370.

[13] C.R. Cunningham, S. Wikshåland, F. Xu, N. Kemakolam, A. Shokrani, V. Dhokia, S.T. Newman, Cost Modelling and Sensitivity Analysis of Wire and Arc Additive Manufacturing, Procedia Manuf. 11 (2017) 650-657. https://doi.org/https://doi.org/10.1016/j.promfg.2017.07.163.

[14] A. Zavdoveev, M. Rogante, V. Poznyakov, M. Heaton, P. Acquier, H.S. Kim, T. Baudin, V. Kostin, Development of the PC-GMAW welding technology for TMCP steel in accordance with welding thermal cycle, welding technique, structure, and properties of welded joints, Reports Mech. Eng. 1 (2020) 26-33. https://www.frontpres.rabek.org/index.php/asd/article/view/3.

[15] A. Zavdoveev, V. Poznyakov, T. Baudin, M. Heaton, H.S. Kim, P. Acquier, M. Skory, M. Rogante, A. Denisenko, Welding Thermal Cycle Impact on the Microstructure and Mechanical Properties of Thermo-Mechanical Control Process Steels, Steel Res. Int. (2021). https://doi.org/10.1002/srin.202000645.

[16] Y.N. Saraev, S.A. Solodskiy, O. V Ulyanova, Improving Processes of 
Mechanized Pulsed Arc Welding of Low-Frequency Range Variation of Mode Parameters, IOP Conf. Ser. Mater. Sci. Eng. 127 (2016) 12019.

https://doi.org/10.1088/1757-899x/127/1/012019.

[17] W.G. Essers, M.R.M. Van Gompel, Arc control with pulsed GMA welding, Weld. J. 63 (1984) 26-32.

[18] K. Wu, N. Ding, T. Yin, M. Zeng, Z. Liang, Effects of single and double pulses on microstructure and mechanical properties of weld joints during high-power double-wire GMAW, J. Manuf. Process. 35 (2018) 728-734.

https://doi.org/https://doi.org/10.1016/j.jmapro.2018.08.025.

[19] S.S. Bargujer, P. Singh, V. Raizada, Thermoprocessing and wire drawing behaviour of ultra high strength steel wires, Perspect. Sci. 8 (2016) 554-557. https://doi.org/10.1016/J.PISC.2016.06.018.

[20] G. Hong, A.S. Holmes, M.E. Heaton, SU8 resist plasma etching and its optimisation, in: Symp. Des. Test, Integr. Packag. MEMS/MOEMS 2003., IEEE, 2003: pp. 268-271. https://doi.org/10.1109/DTIP.2003.1287050.

[21] P.J. Ross, Taguchi Techniques For Quality Engineering: Loss Function, Orthogonal Experiments, Parameter And Tolerance Design, in: 1988.

[22] M.S. Phadke, Quality Engineering Using Robust Design, 1st ed., Prentice Hall PTR, USA, 1995.

[23] Y. Wang, N. Do, Optimization of the polypyrrole-coating parameters for proton exchange membrane fuel cell bipolar plates using the Taguchi method, J.

Power Sources. 185 (2008) 226-232.

https://doi.org/10.1016/j.jpowsour.2008.07.036.

[24] Y. Ma, H. Hu, D. Northwood, X. Nie, Optimization of the electrolytic plasma oxidation processes for corrosion protection of magnesium alloy AM50 using the Taguchi method, J. Mater. Process. Tech. 182 (2007) 58-64. https://doi.org/10.1016/j.jmatprotec.2006.07.007.

[25] M. Yousefieh, M. Shamanian, A. Saatchi, Optimization of the pulsed current gas tungsten arc welding (PCGTAW) parameters for corrosion resistance of 
super duplex stainless steel (UNS S32760) welds using the Taguchi method, J. Alloys Compd. 509 (2011) 782-788.

https://doi.org/https://doi.org/10.1016/j.jallcom.2010.09.087.

[26] D.-X. Peng, Optimization of chemical mechanical polishing parameters on surface roughness of steel substrate with aluminum nanoparticles via Taguchi approach, Ind. Lubr. Tribol. 66 (2014) 685-690. https://doi.org/10.1108/ILT-072012-0063. 